\title{
Comparison of great artery dimensions in 3-D dual-phase SSFP, compared with 3D CE-MRA and phase-contrast imaging (magnitude image)
}

\author{
Aimin Sun², Srinivas Ananth Narayan ${ }^{1 *}$, Gerald F Greil ${ }^{1}$, Tarique Hussain², Kuberan Pushparajah², Aaron Bell ${ }^{1}$, \\ Sujeev Mathur ${ }^{1}$, Reza Razavi ${ }^{1}$
}

From 18th Annual SCMR Scientific Sessions

Nice, France. 4-7 February 2015

\section{Background}

The dimensions of great vessels are measured in different methods in different institutes. The purpose of this study was to evaluate the benefits of 3D dual phase steady-state free-precession(3D-DP SSFP)for measuring great arteries dimension, compared with 3D contrastenhanced magnetic resonance angiography (3D CEMRA) and 2D phase contrast imaging (Magnitude image) (2DPC-MI), in order to find which was the most suitable and reproducible technique for follow-up.

\section{Methods}

29 patients with repaired Tetralogy of Fallot or complete transposition of the great arteries after arterial switch operation (mean age $6.5 \mathrm{yrs}$; range $6 \mathrm{~m}$ to $25 \mathrm{yrs}$ ) were included in the study. Cross-sectional diameter and area measurements were taken of the ascending aorta (Ao), main pulmonary (MPA) and branch pulmonary arteries (BPA) by using 3D DP SSFP, 3D CE-MRA and magnitude image of 2DPC-MI. Image quality was scored by a five-point scale $(0=$ invisible to $4=$ excellent $)$. Statistical comparison between 3D DP SSFP and other two techniques (2DPC-MI and 3D CE-MRA) was performed by using paired-t tests and Intraclass correlation coefficient.

\section{Results}

All great artery cross-sectional measurements were significantly $(\mathrm{P}<0.001)$ greater in systole than in diastole. Measurements (diameter and area) of great arteries were greatest for 2DPC-MI, followed by 3D SSFP in systole and 3D CE-MRA, and smallest for 3D DP SSFP in

\footnotetext{
'Paediatric Cardiology, Evelina London Children's Hospital, Harrow, UK Full list of author information is available at the end of the article
}

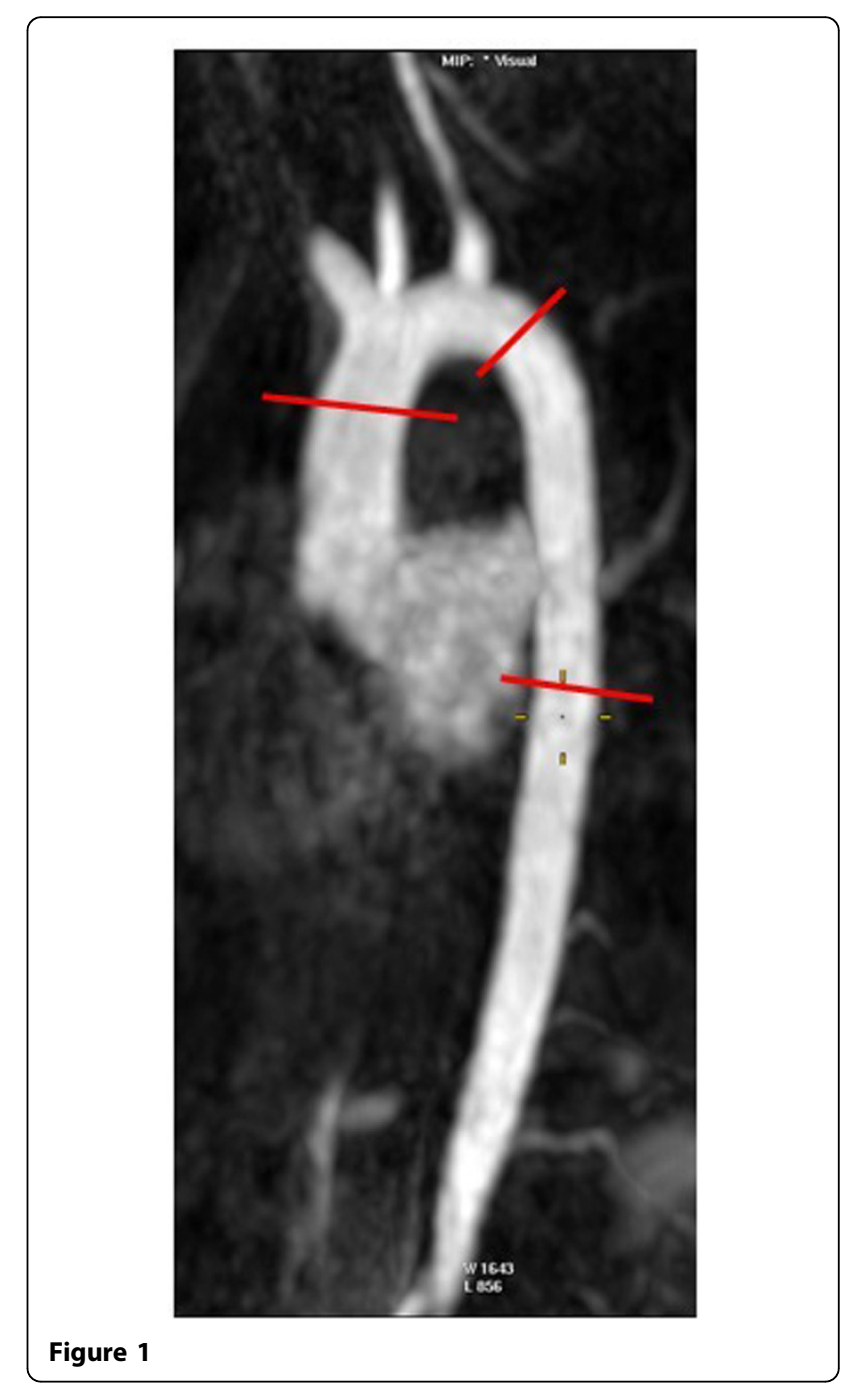



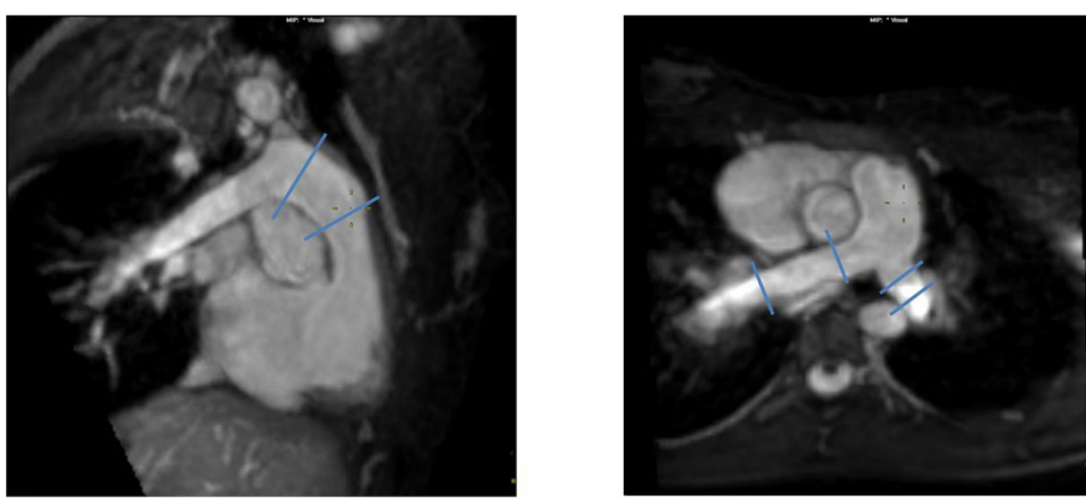

Figure 2

diastole. There was no significant difference of aortic measurements between 3D DP SSFP in systole and 3D CE-MRA, but significance was observed between 3D DP SSFP in systole and 2D PC-MI $(\mathrm{P}<0.05)$. The measurements of MPA and BPA showed no significant difference for 3D DP SSFP in systole compared to other two techniques. Intra-observer agreement of aortic measurements was uniformly $>0.95$, with 2DPC-MI being the best, followed closely by 3D DP SSFP in systole, and 3D CEMRA being the worst. The average image quality of 3D DP SSFP and 2DPC-MI were $\geq 3$. But the image quality was significantly poorer for 3D CE-MRA compared to other two techniques $(\mathrm{P}<0.001)$.

\section{Conclusions}

All Ao and PA cross-sectional measurements were significantly $(\mathrm{P}<0.001)$ greater in systole than in diastole. Measurements of Ao and PA were greatest for 2DPC-MI, followed by 3D SSFP in systole and 3D CE-MRA, and smallest for 3D DP SSFP in diastole. There was no significant difference of aortic measurements between 3D DP SSFP in systole and 3D CE-MRA, but significance was observed between 3D DP SSFP in systole and 2D PC-MI $(\mathrm{P}<0.05)$. The measurements of MPA and BPAs showed no significant difference for 3D DP SSFP in systole compared to other two techniques. Intra-observer agreement of Ao measurements was uniformly $>0.95$, with 2D PCMI being the best, followed closely by 3D DP SSFP in systole, and 3D CE-MRA being the worst. The image quality of 3D DP SSFP and 2D PC-MI scored $\geq 3$. But the image quality was significantly poorer for 3D CE-MRA compared to other two techniques $(\mathrm{P}<0.001)$.

\section{Funding}

The first author recieved an educational grant from Philips Healthcare.

\section{Authors' details}

'Paediatric Cardiology, Evelina London Children's Hospital, Harrow, UK. 2Diagnostic Imaging, Shanghai Children's Medical Centre, Shanghai, China.

Published: 3 February 2015

doi:10.1186/1532-429X-17-S1-P44

Cite this article as: Sun et al:: Comparison of great artery dimensions in 3-D dual-phase SSFP, compared with 3D CE-MRA and phase-contrast imaging (magnitude image). Journal of Cardiovascular Magnetic Resonance 2015 17(Suppl 1):P44.
Submit your next manuscript to BioMed Central and take full advantage of:

- Convenient online submission

- Thorough peer review

- No space constraints or color figure charges

- Immediate publication on acceptance

- Inclusion in PubMed, CAS, Scopus and Google Scholar

- Research which is freely available for redistribution

Submit your manuscript at www.biomedcentral.com/submit
Bïmed Central 